\title{
Targeting Glycogen Synthase Kinase-3 $\beta$ for Therapeutic Benefit against Oxidative Stress in Alzheimer's Disease: Involvement of the Nrf2-ARE Pathway
}

\author{
Katja Kanninen, ${ }^{1,2}$ Anthony R. White, ${ }^{2}$ Jari Koistinaho, ${ }^{1,3,4}$ and Tarja Malm ${ }^{1}$ \\ ${ }^{1}$ Department of Neurobiology, A.I. Virtanen Institute for Molecular Sciences, University of Eastern Finland, P.O. Box 1627, \\ 70211 Kuopio, Finland \\ ${ }^{2}$ Department of Pathology, The University of Melbourne, Melbourne, VIC 3010, Australia \\ ${ }^{3}$ School of Pharmacy, University of Eastern Finland, P.O. Box 1627, 70211 Kuopio, Finland \\ ${ }^{4}$ Department of Oncology, Kuopio University Hospital, P.O. Box 1777, 70211 Kuopio, Finland \\ Correspondence should be addressed to Katja Kanninen, katjak@unimelb.edu.au
}

Received 29 December 2010; Accepted 1 March 2011

Academic Editor: Peter Crouch

Copyright ( $\odot 2011$ Katja Kanninen et al. This is an open access article distributed under the Creative Commons Attribution License, which permits unrestricted use, distribution, and reproduction in any medium, provided the original work is properly cited.

Specific regions of the Alzheimer's disease (AD) brain are burdened with extracellular protein deposits, the accumulation of which is concomitant with a complex cascade of overlapping events. Many of these pathological processes produce oxidative stress. Under normal conditions, oxidative stress leads to the activation of defensive gene expression that promotes cell survival. At the forefront of defence is the nuclear factor erythroid 2-related factor 2 (Nrf2), a transcription factor that regulates a broad spectrum of protective genes. Glycogen synthase kinase- $3 \beta$ (GSK-3 $\beta$ ) regulates Nrf2, thus making this kinase a potential target for therapeutic intervention aiming to boost the protective activation of $\mathrm{Nrf2}$. This paper aims to review the neuroprotective role of $\mathrm{Nrf} 2 \mathrm{in} \mathrm{AD}$, with special emphasis on the role of GSK-3 $\beta$ in the regulation of the Nrf2 pathway. We also examine the potential of inducing GSK$3 \beta$ by small-molecule activators, dithiocarbamates, which potentially exert their beneficial therapeutic effects via the activation of the Nrf2 pathway.

\section{Alzheimer's Disease and Oxidative Stress}

Alzheimer's disease is a common age-associated dementia characterized by pathological, progressive loss of neurons and synapses, accumulation of intra- and extracellular protein deposits, and gliosis. The amyloid hypothesis of $\mathrm{AD}$ postulates that amyloid-beta $(\mathrm{A} \beta)$ deposition and neurotoxicity play a causative role in $\mathrm{AD}$ [1]. Although the mechanisms through which $\mathrm{A} \beta$ exerts its toxicity are numerous [2], it appears that oxidative injury is central in the pathogenesis of $\mathrm{AD}$ [3-5].

Oxidative stress results from an imbalance between the production and removal of physiologically important molecules collectively called reactive oxygen species (ROS) [6-8]. Oxidative stress damages all cellular macromolecules and when uncontrolled, leads to irreparable oxidative injury and cell death. The imbalance between the production and removal of ROS occurs when endogenous defence systems are overwhelmed or exhausted, usually due to disease or as part of normal aging. It is thus not surprising that oxidative stress is involved in the pathogenesis of several neurodegenerative disorders, including AD.

Oxidative stress is a central feature of $\mathrm{AD}$, and, in fact, it may even be one of the first pathogenic events during disease progression [5]. Markers of oxidative damage such as protein carbonyls $[9,10]$ and elevated lipid peroxidation $[11,12]$ precede pathological changes and are found in the brains of $\mathrm{AD}$ patients. Importantly, antioxidant defence is impaired in mouse models of $\mathrm{AD}$; the levels and activities of protective enzymes including superoxide dismutase (SOD) and glutathione peroxidase are altered [13]. 


\section{GSK-3 $\beta$ and AD}

GSK-3 $\beta$ is a serine/threonine kinase that regulates diverse cellular functions ranging from glycogen metabolism to gene transcription and cell survival $[14,15]$.

Several lines of evidence directly link GSK-3 $\beta$ to the neuropathology of $\mathrm{AD}[14,16,17]$. In fact, the recently described GSK hypothesis of AD depicts how overactivation of GSK-3 $\beta$ accounts for the pathology of AD [16]. GSK-3 $\beta$ expression is elevated in the brain of $\mathrm{AD}$ patients and is implicated with at least three major pathological hallmarks of the disease $[18,19]$. First, overactivity of GSK-3 $\beta$ accounts, at least in part, for tau hyperphosphorylation [20]. In human brain, active GSK-3 $\beta$ has been detected in neurons loaded with neurofibrillary tangles [21], and in vitro evidence link increased GSK-3 $\beta$ activation to tau hyperphosphorylation. In fact, $A \beta$ can activate GSK- $3 \beta$, leading eventually to increased tau phosphorylation and loss of microtubule binding. In agreement with the in vitro evidence, mice overexpressing GSK-3 $\beta$ display prominent tau hyperphosphorylation [22]. Secondly, acetylcholine synthesis is suppressed by GSK-3 $\beta$, thus implicating the kinase in the cholinergic deficit characteristic of the disease [23]. This effect has been shown to be mediated by GSK-3 $\beta$-dependent inactivation of pyruvate dehydrogenase (PDH), leading to the depletion of acetyl coenzyme A, an important precursor in acetylcholine synthesis [23]. Thirdly, overactivity of the kinase causes increased production of toxic $\mathrm{A} \beta$. GSK-3 $\beta$ has been shown to interact with presenilin, thus increasing the production of the amyloid precursor protein (APP) and subsequently toxic $A \beta$. The increased production of $A \beta$ then leads to synaptic deficits and memory impairment [24-27]. GSK-3 $\beta$ can also directly phosphorylate APP in vitro [28], and, interestingly, AD-related mutated presenilin-1 is able to both directly and indirectly activate GSK-3 $\beta[29,30]$. Not surprisingly, the inhibition of GSK-3 $\beta$ blocks the accumulation of $\mathrm{A} \beta$ and reduces plaque burden in transgenic mice modelling AD [24], while the overexpression of GSK$3 \beta$ causes memory deficits $[31,32]$. Certain antibodies that reduce brain $\mathrm{A} \beta$ burden also mediate their protective effect by inhibiting GSK-3 $\beta$ activation [33]. Finally, GSK-3 $\beta$ is an important mediator of apoptosis [34], thus its dysregulation may also directly contribute to $\mathrm{AD}$-associated neuronal loss.

GSK-3 $\beta$ phosphorylates a diverse group of substrates, including over 20 transcription factors $[14,35]$. It is hypothesized that GSK-3 $\beta$-mediated impaired activation of transcription factors compromises the ability of cells to respond adequately to stressful conditions. Indeed, GSK-3 $\beta$ is inhibitory towards the activation of transcription factors such as heat shock factor-1 $[36,37]$ and cyclic AMP response element-binding protein $[14,38]$, which are important in cell survival mechanisms after potentially toxic insults [39-41]. However, it is important to note that GSK- $3 \beta$ activation may also affect cell survival by other mechanisms. For example, activated GSK-3 $\beta$ can inactivate an important mediator in the citric acid cycle, PDH, and may thus impair the energy supply in neurons [23].

As the majority of the transcription factors controlled by GSK-3 $\beta$ are involved in cellular survival pathways, the modulation of transcription factors by GSK-3 $\beta$ is likely an important survival mechanism against various stresses, including oxidative stress. It is interesting to note that oxidative stress itself may also be related to GSK-3 $\beta$ activation. For example, oxidative stress induces overactivation of GSK$3 \beta$ in neuronal cells [42], while the inhibition of GSK-3 $\beta$ is involved in the control of oxidative stress in neuronal hippocampal cell lines [43].

\section{Endogenous Defence against Oxidative Stress}

Under normal conditions, oxidative stress leads to the activation of a battery of defensive gene expression that leads to detoxification, prevention of free radical generation and cell survival [44]. At the forefront of defence against oxidative stress is the transcription factor named nuclear factor erythroid 2-related factor (Nrf) 2. Human Nrf2 was first isolated in 1994 from a hemin-induced K562 erythroid cell line and showed high sequence specificity to the known p45 subunit of NF-E2 $[45,46]$. Nrf2 regulates a broad spectrum of enzymes and proteins involved in the disposition of harmful compounds causing oxidative stress. The classes of genes regulated by Nrf2 affect such diverse functions as detoxification of electrophiles, free radical metabolism, glutathione metabolism, proteasome function, and calcium homeostasis [47]. Microarray analyses have revealed numerous Nrf2-dependent genes that confer protection against oxidative stress in vitro $[48,49,49,50]$. Some of the well-characterized cytoprotective genes controlled by $\mathrm{Nrf} 2$ include heme oxygenases (HOs), NAD(P)H: quinone oxidoreductases, superoxide dismutases (SODs) and the rate-limiting enzymes of glutathione synthesis consisting of catalytic (GCLC) and modifier (GCLM) subunits [51-53].

Transcription factors such as Nrf2 are considered key targets of numerous signalling pathways because they have the critical role of transferring information from the extracellular environment to the nucleus to regulate multiple functions. The induction of the Nrf2-controlled protective response requires at least three essential components; antioxidant response elements (AREs), Nrf2, and Kelch ECH-associating protein 1 (Keap1) [47]. AREs are enhancer sequences that control the basal and inducible expression of protective genes in response to oxidative stress, xenobiotics, heavy metals and ultraviolet light $[44,54,55]$. Nrf2 is the principal transcription factor that binds to the ARE and induces the expression of ARE-driven cytoprotective genes. Keap 1 is a cytosolic, actin-associated protein that suppresses the activity of $\mathrm{Nrf} 2$ by sequestering it in the cytoplasm and by targeting it for proteasomal degradation.

The abundance of Nrf2 inside the nucleus is constantly regulated by positive and negative stimuli that affect nuclear import and export, binding to the ARE, as well as the degradation of Nrf2 [44]. It is well known that Keap1 [56] is an inhibitor of Nrf2 that targets Nrf2 for degradation and thus promotes low, basal expression of cytoprotective genes under normal physiological conditions. Previously, it was thought that oxidative stimuli activate Nrf2 by promoting its dissociation from Keap1; however, as the binding affinity between the two proteins is not affected by oxidative stress 
[57-59], it is now understood that the main function of Keap1 is to serve as an adapter for the Cullin3/Ring Box 1 E3 ubiquitin ligase complex $[60,61]$. Keap1 binding to Cullin3 and $\mathrm{Nrf} 2$ leads to the ubiquitination and degradation of Nrf2 through the $26 \mathrm{~S}$ proteasome $[62,63]$. Keap1 also functions as ROS sensor molecule, the cysteine residues of which are modified upon conditions of oxidative stress [64, 65]. Oxidative stress impairs the ability of Keap1 to target Nrf2 for degradation, most likely by triggering an alteration in Keap 1 conformation.

\section{Nrf2 in AD}

The activation of the Nrf2-ARE pathway is beneficial in animal models of various diseases of the central nervous system, including chronic neurodegenerative diseases such as Parkinson's disease and acute insults such as brain ischemia and brain trauma [66-69]. However, in comparison to other neurodegenerative disorders, the role of Nrf2 in $\mathrm{AD}$ has received relatively little attention. Currently, it is known that while Nrf2 is not a susceptibility gene for $\mathrm{AD}$, common variants of the gene encoding Nrf2 may affect disease progression [70]. In the human AD brain, the amount of nuclear Nrf2 is reduced in the hippocampus [71]. Histochemical analyses demonstrate that Nrf2 predominantly localizes to the cytoplasm of AD-affected hippocampal neurons, suggesting that despite oxidative stress, Nrf2-mediated transcription is not induced in $\mathrm{AD}$ patients. However, this study utilized brain tissue demonstrating full-blown $\mathrm{AD}$ pathology; it is not clear whether the finding is a cause or consequence of the ongoing pathological events and cell death. In fact, it has been suggested that the induction of Nrf2, and levels and activity of its cytoprotective target enzymes may display a time-dependent alteration in $\mathrm{AD}$ [66].

We recently showed that attenuation of the Nrf2-ARE pathway coincides with disease progression in the APdE9 transgenic mice modelling $\mathrm{AD}$ [72]. The Nrf2-pathway was impaired in transgenic AD mice concomitantly with increased brain $\mathrm{A} \beta$ burden. This $\mathrm{AD}$-associated reduction in Nrf2 was recently confirmed by Choudry et al., who described a $50 \%$ reduction in Nrf2 levels in transgenic $\mathrm{AD}$ mice [73].

A growing body of literature suggests that $\mathrm{Nrf} 2$ is neuroprotective in AD. Induction of the Nrf2-ARE pathway by small therapeutic molecules protects against neuronal dysfunction and toxicity mediated by $\mathrm{A} \beta$ in vitro $[72,74-$ 76]. Interestingly, $\mathrm{Nrf} 2$ can also exert its protective effects by suppressing oxidative stress-induced $\mathrm{A} \beta$ formation $[74,77]$ and by inducing the $26 \mathrm{~S}$ proteasome, thus facilitating the removal of toxic $A \beta$ [78]. Protection against $A \beta$ toxicity by coffee extract has also been shown to occur via the induction of the Nrf2-ARE pathway in Caenorhabditis elegans [79].

In addition to assessing the effect of small molecule inducers of the Nrf2-ARE pathway on $\mathrm{A} \beta$ toxicity, we recently studied therapeutic and disease-modifying properties of Nrf2-ARE induction by gene transfer in transgenic mice modelling $\mathrm{AD}$ [80]. The long-term effect of Nrf2-ARE activation was studied in vivo by employing a gene therapy approach where human Nrf2 was directly injected into the hippocampi of transgenic AD mice, an area of the brain important for learning and memory that is directly affected by $\mathrm{AD}$ pathology. Evident improvement in cognitive abilities was achieved when transgenic $\mathrm{AD}$ mice were treated with the Nrf2 vector at the age of 9 months and assessed in the Morris water maze 6 months later. This effect was associated with the induction of the Nrf2-pathway, suggesting that strategies aimed at boosting the Nrf2-ARE pathway constitute a potential therapeutic approach for $\mathrm{AD}$.

\section{GSK-3 $\beta$ in the Regulation of the Nrf2-ARE Pathway}

As GSK-3 $\beta$ controls a variety of targets in several cellular pathways, it is not surprising that the kinase is also implicated in the regulation of Nrf2. GSK-3 $\beta$ exerts a negative form of regulation on Nrf2 by controlling it is subcellular distribution [81] (Figure 1). Long-term exposure to hydrogen peroxide causes downregulation of Akt, activation of GSK-3 $\beta$, and translocation of Nrf2 from the nucleus to the cytosol, thus limiting the antioxidant response of cells [82]. This is particularly important in conditions of prolonged oxidative stress, such as $\mathrm{AD}$, and highlights the importance of this kinase in chronic neurodegenerative disorders. The inhibition of GSK- $3 \beta$ results in nuclear accumulation and the elevation of transcriptional activity of $\mathrm{Nrf2}$ [82], indicating that GSK-3 $\beta$ is a fundamental element of Nrf2-ARE downregulation after oxidative injury. The mechanism of GSK-3 $\beta$-mediated Nrf2 inhibition appears to involve the tyrosine kinase Fyn, which is phosphorylated by activated GSK- $3 \beta$ and leads to nuclear localization of Fyn. Activated Fyn phosphorylates tyrosine 568 of Nrf2 [83] in the nucleus, leading to Nrf2 export and dampening of protective gene transcription $[83,84]$. Once excluded from the nucleus, Nrf2 is degraded. Very recently, it was shown that transfection with a constitutively active genetic variant of GSK- $3 \beta$ completely inhibits nuclear accumulation of Nrf2, providing further support for the role of GSK-3 $\beta$ in controlling Nrf2 activation [85].

Further evidence for the importance of GSK-3 $\beta$ in the regulation of Nrf2 is demonstrated by the finding that activation of the muscarinic M1 receptor induces Nrf2 through a signalling cascade involving protein kinase $\mathrm{C}$-mediated inhibition of GSK-3 $\beta$ [86]. Moreover, GSK- $3 \beta$ is known to regulate oxidative stress protein SKN-1, the functional counterpart of Nrf2, in Caenorhabditis elegans [87]. Taken together, these data suggest that increased activation of GSK-3 $\beta$ leads to a dampening of the protective Nrf2-ARE pathway.

\section{Dithiocarbamates as Nrf2-Inducing Pharmacological Agents Targeted to GSK-3 $\beta$ Activation}

Stimulation of the Nrf2-ARE pathway by small-molecule activators represents an appealing strategy to upregulate the endogenous defence mechanism of cells against oxidative stress. At least nine classes of Nrf2 inducers have been described [88] and several of these are protective in models of neurodegenerative diseases. However, more potent, safe, 


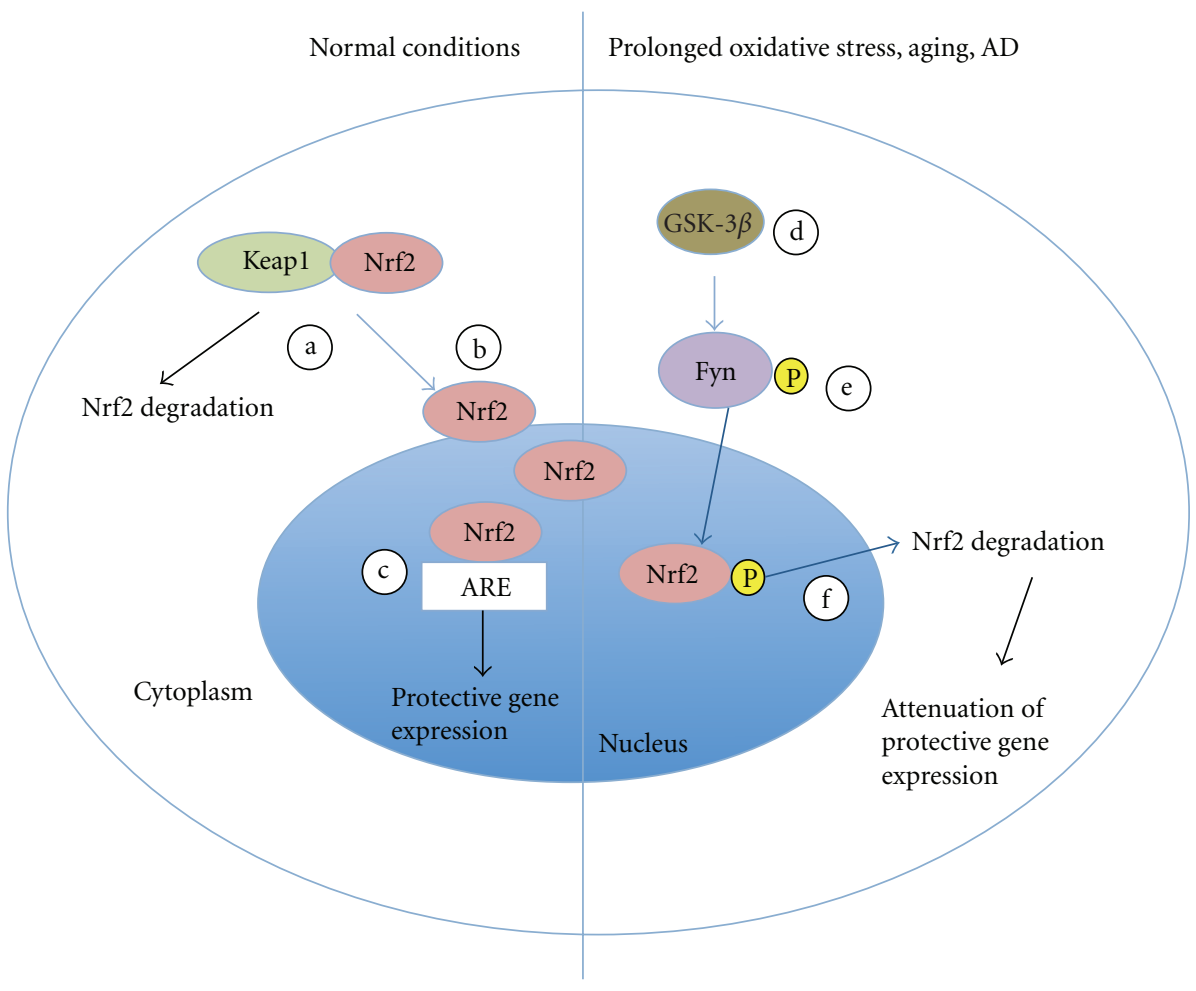

FIGURE 1: Induction of the Nrf2-ARE pathway under normal and pathological conditions: potential role of GSK-3 $\beta$ as a negative regulator of Nrf2. (a) In normal conditions, actin-associated Keap1 sequesters Nrf2 in the cytosol and targets it for degradation. (b) Endogenously and exogenously generated ROS alter the interaction between Nrf2 and its repressor, resulting in the accumulation of Nrf2 in the cytoplasm. Nrf2 translocates into the nucleus. (c) An abundance of Nrf2 in the nucleus results in the binding of Nrf2 to the ARE and the increased expression of protective, Nrf2-controlled genes. (d) In conditions of prolonged oxidative stress, GSK-3 $\beta$ is activated. (e) Activated GSK-3 $\beta$ phosphorylates Fyn, causing nuclear translocation. (f) Nuclear Fyn phosphorylates Nrf2, leading to nuclear export of Nrf2 and degradation in the cytosol.

and specific activators of the Nrf2-ARE pathway that cross the blood brain barrier (BBB) need to be explored in relevant models of AD.

Dithiocarbamates are attractive drug candidates for many diseases as they are BBB permeant metal chelating compounds that possess antioxidant and anti-inflammatory properties [89] and are clinically approved for treatment of alcohol addiction (Antabus) and heavy metal poisoning. In addition to its well-characterized role in the inhibition of nuclear factor $-\kappa \mathrm{B}[90,91]$, pyrrolidine dithiocarbamate (PDTC) has potent antioxidant properties and is able to scavenge ROS [90-93]. It is becoming increasingly evident that PDTC also has the potential to activate endogenous antioxidant gene expression. In vitro studies suggest that PDTC treatment results in the activation and nuclear translocation of Nrf2 $[94,95]$. Moreover, the cytoprotective, Nrf2-controlled proteins, HO-1, GCLM, and SOD, are potently induced in response to PDTC in vitro [94, 96-98]. Interestingly, it has also been shown that PDTC can act as a pro-oxidant [99]. Indeed, PDTC induces apoptosis in several in vitro models $[100,101,101,102]$ and may also be toxic to neurons in vivo [103]. Whether the action of PDTC is anti- or pro-oxidant has been reported to depend on the dose of PDTC and the presence of metal ions [104]. It may well be that PDTC can exert its effects on Nrf2-mediated gene transcription by mimicking an oxidative insult (and thus acting as a pro-oxidant) that triggers Nrf2 activation.

PDTC is known to reduce activated GSK- $3 \beta$ signalling in neonatal hypoxia-ischemia [105]. We also showed that while the activity of GSK-3 $\beta$ is increased in the brains of transgenic AD mice [106], a 7-month treatment with PDTC reduces the amount of active GSK-3 $\beta$ with concomitant improvement in the spatial learning of the treated mice. This effect may involve the metal-chelating ability of PDTC. It is known that PDTC can transport extracellular copper into cells [107] and depending on the situation at hand, this may have different effects. For example, copper transport into cells is most likely beneficial in AD animal models [108-110], where pools of intracellular copper are depleted or unevenly or inefficiently distributed within the brain parenchyma. In contrast, under normal conditions, an increase in cellular copper levels may cause an increase in free radical production and apoptosis $[111,112]$. As copper can induce the Akt pathway, we hypothesize that the PDTC-mediated increase in intracellular copper could trigger the phosphorylation of Akt, leading to reduced GSK-3 $\beta$ activity.

To analyze the association of $\mathrm{Nrf} 2$ with the beneficial effect of PDTC treatment, we assessed the potential of 
PDTC in protection against $\mathrm{A} \beta$ toxicity in primary cultures prepared from Nrf2 knockout mice. While PDTC protected against $\mathrm{A} \beta$ toxicity in wild-type neuronal cultures, the beneficial effect was abolished in cultures prepared from knock-out mice (Kanninen, $\mathrm{K}$ et al., unpublished data). Moreover, PDTC treatment of neuronal cultures induced Nrf2 target genes (Kanninen, $\mathrm{K}$ et al., unpublished data). Taken together, these data indicate that Nrf2 is required for the beneficial effect of PDTC against $\mathrm{A} \beta$ toxicity in vitro and suggest that Nrf2-ARE induction may be associated with the beneficial effect of PDTC in AD. However, further studies are required to clarify and specify the involvement of GSK-3 $\beta$ in aberrant regulation of $\mathrm{Nrf} 2$ in $\mathrm{AD}$.

\section{Targeting GSK-3 $\beta$ for Therapeutic Benefit in AD: Involvement of the Nrf2-ARE Pathway}

While the detailed mechanisms behind the impairment of the Nrf2-ARE pathway in transgenic AD mice remain unresolved, it is possible that it involves GSK- $3 \beta$. Considering that GSK- $3 \beta$ can inactivate Nrf2 $[81,86]$, it is conceivable that the Nrf2-ARE pathway is dampened in the aged AD transgenic mouse brain through the increased activity of GSK- $3 \beta$. In fact, long-term oxidative stress causes GSK-3 $\beta$ activation and reduces nuclear $\mathrm{Nrf2}$, suggestive of downregulation of the Nrf2-ARE pathway [82]. This hypothesis is further supported by the finding that pharmacological treatments, which inhibit GSK-3 $\beta$, have been reported to reduce $A \beta$ pathology and cognitive impairment in $\mathrm{AD}$ mice [24]. Moreover, lithium, a GSK-3 $\beta$ inhibitor, has been shown to promote the transcriptional activity of Nrf2 [82].

While modulating the activity of GSK- $3 \beta$ is known to be beneficial in models of $\mathrm{AD}$, studying the mechanism of action of modulators of the kinase is important in understanding the diverse pathways GSK- $3 \beta$ is involved in and the numerous effects modulation may have. For example, treatment with small molecules such as PDTC prevents cognitive impairment in transgenic AD mice [106], not only by the inhibition of GSK-3 $\beta$, but also potentially via the activation of the Nrf2-ARE pathway.

\section{Concluding Remarks}

Due to the major social and economical burden caused by the aging of populations and the subsequent increase in the incidences of neurodegenerative diseases, potential novel targets for effective $\mathrm{AD}$ therapeutics are urgently needed. Despite extensive research and knowledge that oxidative stress is a central pathological feature of $\mathrm{AD}$, several therapeutic approaches targeted to this aspect of disease have failed, most likely because they have targeted only one aspect such as the decline of a single antioxidant. Considering the complexity of the antioxidant system, it seems reasonable to consider that the induction of endogenous protective pathways, such as the Nrf2-ARE pathway against oxidative stress, is a viable strategy for delaying the progression of injury and cell death.

It is clear that understanding the mechanisms of regulation of the Nrf2-ARE pathway and how these mechanisms are impaired in disease is central in deciphering how we can modulate this protective pathway against oxidative stress associated with $\mathrm{AD}$. While several other regulatory pathways of Nrf2-ARE have been described and GSK-3 $\beta$ modulation in $\mathrm{AD}$ is also known to be beneficial in several ways, studying the influence of GSK-3 $\beta$ on Nrf2-ARE is certainly an important path to pursue in order to better understand how to combat the oxidative stress associated with $\mathrm{AD}$.

\section{Acknowledgments}

The authors thank the Academy of Finland, the Finnish Cultural Foundation, the Orion-Farmos Research Foundation, and the Sigrid Juselius Foundation for their support.

\section{References}

[1] J. A. Hardy and G. A. Higgins, "Alzheimer's disease: the amyloid cascade hypothesis," Science, vol. 256, no. 5054, pp. 184-185, 1992.

[2] P. J. Crouch, S. M. E. Harding, A. R. White, J. Camakaris, A. I. Bush, and C. L. Masters, "Mechanisms of A $\beta$ mediated neurodegeneration in Alzheimer's disease," International Journal of Biochemistry and Cell Biology, vol. 40, no. 2, pp. 181-198, 2008.

[3] D. J. Selkoe, "Alzheimer's disease: genes, proteins, and therapy," Physiological Reviews, vol. 81, no. 2, pp. 741-766, 2001.

[4] X. Zhu, B. Su, X. Wang, M. A. Smith, and G. Perry, "Causes of oxidative stress in Alzheimer disease," Cellular and Molecular Life Sciences, vol. 64, no. 17, pp. 2202-2210, 2007.

[5] A. Nunomura, G. Perry, G. Aliev et al., "Oxidative damage is the earliest event in Alzheimer disease," Journal of Neuropathology and Experimental Neurology, vol. 60, no. 8, pp. 759-767, 2001.

[6] K. J. Barnham, C. L. Masters, and A. I. Bush, "Neurodegenerative diseases and oxidatives stress," Nature Reviews Drug Discovery, vol. 3, no. 3, pp. 205-214, 2004.

[7] D. Praticò, "Evidence of oxidative stress in Alzheimer's disease brain and antioxidant therapy: lights and shadows," Annals of the New York Academy of Sciences, vol. 1147, pp. 70-78, 2008.

[8] M. Valko, D. Leibfritz, J. Moncol, M. T. D. Cronin, M. Mazur, and J. Telser, "Free radicals and antioxidants in normal physiological functions and human disease," International Journal of Biochemistry and Cell Biology, vol. 39, no. 1, pp. 44-84, 2007.

[9] A. Castegna, M. Aksenov, V. Thongboonkerd et al., "Proteomic identification of oxidatively modified proteins in Alzheimer's disease brain-part II: dihydropyrimidinaserelated protein 2, $\alpha$-enolase and heat shock cognate 71 ," Journal of Neurochemistry, vol. 82, no. 6, pp. 1524-1532, 2002.

[10] M. A. Korolainen, G. Goldsteins, I. Alafuzoff, J. Koistinaho, and T. Pirttilä, "Proteomic analysis of protein oxidation in Alzheimer's disease brain," Electrophoresis, vol. 23, no. 19, pp. 3428-3433, 2002.

[11] T. T. Reed, W. M. Pierce, W. R. Markesbery, and D. A. Butterfield, "Proteomic identification of HNE-bound proteins in early Alzheimer disease: insights into the role of lipid peroxidation in the progression of AD," Brain Research, vol. 1274, no. C, pp. 66-76, 2009. 
[12] K. V. Subbarao, J. S. Richardson, and L. S. Ang, "Autopsy samples of Alzheimer's cortex show increased peroxidation in vitro," Journal of Neurochemistry, vol. 55, no. 1, pp. 342$345,1990$.

[13] J. M. Olcese, C. Cao, T. Mori et al., "Protection against cognitive deficits and markers of neurodegeneration by longterm oral administration of melatonin in a transgenic model of Alzheimer disease," Journal of Pineal Research, vol. 47, no. 1, pp. 82-96, 2009.

[14] C. A. Grimes and R. S. Jope, "The multifaceted roles of glycogen synthase kinase $3 \beta$ in cellular signaling," Progress in Neurobiology, vol. 65, no. 4, pp. 391-426, 2001.

[15] J. R. Woodgett, "Molecular cloning and expression of glycogen synthase kinase-3/factor A," EMBO Journal, vol. 9, no. 8, pp. 2431-2438, 1990.

[16] C. Hooper, R. Killick, and S. Lovestone, "The GSK3 hypothesis of Alzheimer's disease," Journal of Neurochemistry, vol. 104, no. 6, pp. 1433-1439, 2008.

[17] S. Hu, A. N. Begum, M. R. Jones et al., "GSK3 inhibitors show benefits in an Alzheimer's disease (AD) model of neurodegeneration but adverse effects in control animals," Neurobiology of Disease, vol. 33, no. 2, pp. 193-206, 2009.

[18] K. Leroy, Z. Yilmaz, and J. P. Brion, "Increased level of active GSK-3 $\beta$ in Alzheimer's disease and accumulation in argyrophilic grains and in neurones at different stages of neurofibrillary degeneration," Neuropathology and Applied Neurobiology, vol. 33, no. 1, pp. 43-55, 2007.

[19] J. J. Pei, T. Tanaka, Y. C. Tung, E. Braak, K. Iqbal, and I. Grundke-Iqbal, "Distribution, levels, and activity of glycogen synthase kinase-3 in the Alzheimer disease brain," Journal of Neuropathology and Experimental Neurology, vol. 56, no. 1, pp. 70-78, 1997.

[20] F. Plattner, M. Angelo, and K. P. Giese, "The roles of cyclindependent kinase 5 and glycogen synthase kinase 3 in tau hyperphosphorylation," Journal of Biological Chemistry, vol. 281, no. 35, pp. 25457-25465, 2006.

[21] J. J. Pei, E. Braak, H. Braak et al., "Distribution of active glycogen synthase kinase $3 \beta(\mathrm{GSK}-3 \beta)$ in brains staged for Alzheimer disease neurofibrillary changes," Journal of Neuropathology and Experimental Neurology, vol. 58, no. 9, pp. 1010-1019, 1999.

[22] J. J. Lucas, F. Hernández, P. Gómez-Ramos, M. A. Morán, R. Hen, and J. Avila, "Decreased nuclear $\beta$-catenin, tau hyperphosphorylation and neurodegeneration in GSK-3 $\beta$ conditional transgenic mice," EMBO Journal, vol. 20, no. 1-2, pp. 27-39, 2001.

[23] M. Hoshi, A. Takashima, K. Noguchi et al., "Regulation of mitochondrial pyruvate dehydrogenase activity by tau protein kinase I/glycogen synthase kinase $3 \beta$ in brain," Proceedings of the National Academy of Sciences of the United States of America, vol. 93, no. 7, pp. 2719-2723, 1996.

[24] C. J. Phiel, C. A. Wilson, V. M.-Y. Lee, and P. S. Klein, "GSK$3 \alpha$ regulates production of Alzheimer's disease amyloid- $\beta$ peptides," Nature, vol. 423, no. 6938, pp. 435-439, 2003.

[25] A. Takashima, K. Noguchi, G. Michel et al., "Exposure of rat hippocampal neurons to amyloid $\beta$ peptide (25-35) induces the inactivation of phosphatidyl inositol-3 kinase and the activation of tau protein kinase I/glycogen synthase kinase3ß," Neuroscience Letters, vol. 203, no. 1, pp. 33-36, 1996.

[26] L. Baki, R. L. Neve, Z. Shao, J. Shioi, A. Georgakopoulos, and N. K. Robakis, "Wild-type but not FAD mutant presenilin1 prevents neuronal degeneration by promoting phosphatidylinositol 3-kinase neuroprotective signaling," Journal of Neuroscience, vol. 28, no. 2, pp. 483-490, 2008.
[27] S. Peineau, C. Taghibiglou, C. Bradley et al., "LTP inhibits LTD in the hippocampus via regulation of GSK $3 \beta$," Neuron, vol. 53, no. 5, pp. 703-717, 2007.

[28] A. E. Aplin, G. M. Gibb, J. S. Jacobsen, J. M. Gallo, and B. H. Anderton, "In vitro phosphorylation of the cytoplasmic domain of the amyloid precursor protein by glycogen synthase kinase-3 $\beta$," Journal of Neurochemistry, vol. 67, no. 2, pp. 699-707, 1996.

[29] A. Takashima, M. Murayama, O. Murayama et al., "Presenilin 1 associates with glycogen synthase kinase- $3 \beta$ and its substrate tau," Proceedings of the National Academy of Sciences of the United States of America, vol. 95, no. 16, pp. 9637-9641, 1998.

[30] C. C. Weihl, G. D. Ghadge, S. G. Kennedy, N. Hay, R. J. Miller, and R. P. Roos, "Mutant presenilin-1 induces apoptosis and downregulates Akt/PKB," Journal of Neuroscience, vol. 19, no. 13, pp. 5360-5369, 1999.

[31] T. Engel, F. Hernández, J. Avila, and J. J. Lucas, "Full reversal of Alzheimer's disease-like phenotype in a mouse model with conditional overexpression of glycogen synthase kinase-3," Journal of Neuroscience, vol. 26, no. 19, pp. 5083-5090, 2006.

[32] F. Hernández, J. Borrell, C. Guaza, J. Avila, and J. J. Lucas, "Spatial learning deficit in transgenic mice that conditionally over-express GSK-3 $\beta$ in the brain but do not form tau filaments," Journal of Neurochemistry, vol. 83, no. 6, pp. 15291533, 2002.

[33] Q.-L. Ma, G. P. Lim, M. E. Harris-White et al., "Antibodies against $\beta$-amyloid reduce $\mathrm{A} \beta$ oligomers, glycogen synthase kinase- $3 \beta$ activation and $\tau$ phosphorylation in vivo and in vitro," Journal of Neuroscience Research, vol. 83, no. 3, pp. 374-384, 2006.

[34] G. A. Turenne and B. D. Price, "Glycogen synthase kinase3 beta phosphorylates serine 33 of p53 and activates p53's transcriptional activity," BMC Cell Biology, vol. 2, no. 1, article 12, p. 12, 2001.

[35] R. S. Jope and G. V. W. Johnson, "The glamour and gloom of glycogen synthase kinase-3," Trends in Biochemical Sciences, vol. 29, no. 2, pp. 95-102, 2004.

[36] G. N. Bijur and R. S. Jope, "Opposing actions of phosphatidylinositol 3-kinase and glycogen synthase kinase- $3 \beta$ in the regulation of HSF-1 activity," Journal of Neurochemistry, vol. 75, no. 6, pp. 2401-2408, 2000.

[37] B. He, Y.-H. Meng, and N. F. Mivechi, "Glycogen synthase kinase $3 \beta$ and extracellular signal-regulated kinase inactivate heat shock transcription factor 1 by facilitating the disappearance of transcriptionally active granules after heat shock," Molecular and Cellular Biology, vol. 18, no. 11, pp. 6624-6633, 1998.

[38] B. P. Bullock and J. F. Habener, "Phosphorylation of the cAMP response element binding protein CREB by cAMPdependent protein kinase A and glycogen synthase kinase-3 alters DNA-binding affinity, conformation, and increases net charge," Biochemistry, vol. 37, no. 11, pp. 3795-3809, 1998.

[39] D. Jean, M. Harbison, D. J. McConkey, Z. Ronai, and M. BarEli, "CREB and its associated proteins act as survival factors for human melanoma cells," Journal of Biological Chemistry, vol. 273, no. 38, pp. 24884-24890, 1998.

[40] R. S. Struthers, W. W. Vale, C. Arias, P. E. Sawchenko, and M. R. Montminy, "Somatotroph hypoplasia and dwarfism in transgenic mice expressing a non-phosphorylatable CREB mutant," Nature, vol. 350, no. 6319, pp. 622-624, 1991. 
[41] C. A. Grimes and R. S. Jope, "Creb DNA binding activity is inhibited by glycogen synthase kinase- $3 \beta$ and facilitated by lithium," Journal of Neurochemistry, vol. 78, no. 6, pp. 12191232, 2001.

[42] K. Y. Lee, S. H. Koh, M. Y. Noh, K. W. Park, Y. J. Lee, and S. H. Kim, "Glycogen synthase kinase- $3 \beta$ activity plays very important roles in determining the fate of oxidative stressinflicted neuronal cells," Brain Research, vol. 1129, no. 1, pp. 89-99, 2007.

[43] M. Schäfer, S. Goodenough, B. Moosmann, and C. Behl, "Inhibition of glycogen synthase kinase $3 \beta$ is involved in the resistance to oxidative stress in neuronal HT22 cells," Brain Research, vol. 1005, no. 1-2, pp. 84-89, 2004.

[44] J. W. Kaspar, S. K. Niture, and A. K. Jaiswal, "Nrf2:INrf2 (Keap1) signaling in oxidative stress," Free Radical Biology and Medicine, vol. 47, no. 9, pp. 1304-1309, 2009.

[45] J. Y. Chan, X. L. Han, and Y. W. Kan, "Isolation of cDNA encoding the human NF-E2 protein," Proceedings of the National Academy of Sciences of the United States of America, vol. 90, no. 23, pp. 11366-11370, 1993.

[46] P. Moi, K. Chan, I. Asunis, A. Cao, and Y. W. Kan, "Isolation of NF-E2-related factor 2 (Nrf2), a NF-E2-like basic leucine zipper transcriptional activator that binds to the tandem NF-E2/AP1 repeat of the $\beta$-globin locus control region," Proceedings of the National Academy of Sciences of the United States of America, vol. 91, no. 21, pp. 9926-9930, 1994.

[47] T. W. Kensler, N. Wakabayashi, and S. Biswal, "Cell survival responses to environmental stresses via the Keap1-Nrf2-ARE pathway," Annual Review of Pharmacology and Toxicology, vol. 47, pp. 89-116, 2007.

[48] J. M. Lee, M. J. Calkins, K. Chan, Y. W. Kan, and J. A. Johnson, "Identification of the NF-E2-related factor2-dependent genes conferring protection against oxidative stress in primary cortical astrocytes using oligonucleotide microarray analysis," Journal of Biological Chemistry, vol. 278, no. 14, pp. 12029-12038, 2003.

[49] J. M. Lee, A. Y. Shih, T. H. Murphy, and J. A. Johnson, "NFE2-related factor-2 mediates neuroprotection against mitochondrial complex I inhibitors and increased concentrations of intracellular calcium in primary cortical neurons," Journal of Biological Chemistry, vol. 278, no. 39, pp. 37948-37956, 2003.

[50] J. Li, J. M. Lee, and J. A. Johnson, "Microarray analysis reveals an antioxidant responsive element-driven gene set involved in conferring protection from an oxidative stress-induced apoptosis in IMR-32 cells," Journal of Biological Chemistry, vol. 277, no. 1, pp. 388-394, 2002.

[51] N. M. Inamdar, Y. I. Ahn, and J. Alam, "The heme-responsive element of the mouse heme oxygenase-1 gene is an extended AP-1 binding site that resembles the recognition sequences for MAF and NF-E2 transcription factors," Biochemical and Biophysical Research Communications, vol. 221, no. 3, pp. 570-576, 1996.

[52] Y. Li and A. K. Jaiswal, "Regulation of human NAD(P)H: quinone oxidoreductase gene: role of AP1 binding site contained within human antioxidant response element," Journal of Biological Chemistry, vol. 267, no. 21, pp. 1509715104, 1992.

[53] R. T. Mulcahy, M. A. Wartman, H. H. Bailey, and J. J. Gipp, "Constitutive and $\beta$-naphthoflavone-induced expression of the human $\gamma$ - glutamylcysteine synthetase heavy subunit gene is regulated by a distal antioxidant response element/TRE sequence," Journal of Biological Chemistry, vol. 272, no. 11, pp. 7445-7454, 1997.
[54] T. Nguyen, P. Nioi, and C. B. Pickett, "The Nrf2-antioxidant response element signaling pathway and its activation by oxidative stress," Journal of Biological Chemistry, vol. 284, no. 20, pp. 13291-13295, 2009.

[55] T. H. Rushmore, M. R. Morton, and C. B. Pickett, "The antioxidant responsive element: activation by oxidative stress and identification of the DNA consensus sequence required for functional activity," Journal of Biological Chemistry, vol. 266, no. 18, pp. 11632-11639, 1991.

[56] K. Itoh, N. Wakabayashi, Y. Katoh et al., "Keap1 represses nuclear activation of antioxidant responsive elements by Nrf2 through binding to the amino-terminal Neh2 domain," Genes and Development, vol. 13, no. 1, pp. 76-86, 1999.

[57] A. L. Eggler, G. Liu, J. M. Pezzuto, R. B. Van Breemen, and A. D. Mesecar, "Modifying specific cysteines of the electrophile-sensing human Keap1 protein is insufficient to disrupt binding to the Nrf2 domain Neh2," Proceedings of the National Academy of Sciences of the United States of America, vol. 102, no. 29, pp. 10070-10075, 2005.

[58] M. Kobayashi and M. Yamamoto, "Nrf2-Keap1 regulation of cellular defense mechanisms against electrophiles and reactive oxygen species," Advances in Enzyme Regulation, vol. 46, no. 1, pp. 113-140, 2006.

[59] K. I. Tong, A. Kobayashi, F. Katsuoka, and M. Yamamoto, "Two-site substrate recognition model for the Keap1-Nrf2 system: a hinge and latch mechanism," Biological Chemistry, vol. 387, no. 10-11, pp. 1311-1320, 2006.

[60] S. B. Cullinan, J. D. Gordan, J. Jin, J. W. Harper, and J. A. Diehl, "The Keap1-BTB protein is an adaptor that bridges Nrf2 to a Cul3-based E3 ligase: oxidative stress sensing by a Cul3-Keap1 ligase," Molecular and Cellular Biology, vol. 24, no. 19, pp. 8477-8486, 2004.

[61] A. Kobayashi, M. I. Kang, H. Okawa et al., "Oxidative stress sensor Keap1 functions as an adaptor for Cul3-based E3 ligase to regulate proteasomal degradation of Nrf2," Molecular and Cellular Biology, vol. 24, no. 16, pp. 7130-7139, 2004.

[62] K. R. Sekhar, X. X. Yan, and M. L. Freeman, "Nrf2 degradation by the ubiquitin proteasome pathway is inhibited by KIAA0132, the human homolog to INrf2," Oncogene, vol. 21, no. 44, pp. 6829-6834, 2002.

[63] D. Stewart, E. Killeen, R. Naquin, S. Alam, and J. Alam, "Degradation of transcription factor Nrf2 via the ubiquitinproteasome pathway and stabilization by cadmium," Journal of Biological Chemistry, vol. 278, no. 4, pp. 2396-2402, 2003.

[64] A. T. Dinkova-Kostova, W. D. Holtzclaw, R. N. Cole et al., "Direct evidence that sulfhydryl groups of Keap1 are the sensors regulating induction of phase 2 enzymes that protect against carcinogens and oxidants," Proceedings of the National Academy of Sciences of the United States of America, vol. 99, no. 18, pp. 11908-11913, 2002.

[65] M. Kobayashi, L. Li, N. Iwamoto et al., "The antioxidant defense system Keap1-Nrf2 comprises a multiple sensing mechanism for responding to a wide range of chemical compounds," Molecular and Cellular Biology, vol. 29, no. 2, pp. 493-502, 2009.

[66] H. E. de Vries, M. Witte, D. Hondius et al., "Nrf2-induced antioxidant protection: a promising target to counteract ROS-mediated damage in neurodegenerative disease?" Free Radical Biology and Medicine, vol. 45, no. 10, pp. 1375-1383, 2008.

[67] N. Tanaka, Y. Ikeda, Y. Ohta et al., "Expression of Keap1Nrf2 system and antioxidative proteins in mouse brain after 
transient middle cerebral artery occlusion," Brain Research, vol. 1370, pp. 246-253, 2011.

[68] W. Jin, H. Wang, W. Yan et al., "Role of Nrf2 in protection against traumatic brain injury in mice," Journal of Neurotrauma, vol. 26, no. 1, pp. 131-139, 2009.

[69] A. Y. Shih, P. Li, and T. H. Murphy, "A small-moleculeinducible Nrf2-mediated antioxidant response provides effective prophylaxis against cerebral ischemia in vivo," Journal of Neuroscience, vol. 25, no. 44, pp. 10321-10335, 2005.

[70] M. von Otter, S. Landgren, S. Nilsson et al., "Nrf2-encoding NFE2L2 haplotypes influence disease progression but not risk in Alzheimer's disease and age-related cataract," Mechanisms of Ageing and Development, vol. 131, no. 2, pp. 105110, 2010.

[71] C. P. Ramsey, C. A. Glass, M. B. Montgomery et al., "Expression of Nrf2 in neurodegenerative diseases," Journal of Neuropathology and Experimental Neurology, vol. 66, no. 1, pp. 75-85, 2007.

[72] K. Kanninen, T. M. Malm, H. K. Jyrkkänen et al., "Nuclear factor erythroid 2-related factor 2 protects against beta amyloid," Molecular and Cellular Neuroscience, vol. 39, no. 3, pp. 302-313, 2008.

[73] F. Choudhry, D. R. Howlett, J. C. Richardson, P. T. Francis, and P. T. Williams, "Pro-oxidant diet enhances beta/gamma secretase-mediated APP processing in APP/PS1 transgenic mice," Neurobiology of Aging. In press.

[74] F. Khodagholi, B. Eftekharzadeh, N. Maghsoudi, and P. F. Rezaei, "Chitosan prevents oxidative stress-induced amyloid $\beta$ formation and cytotoxicity in NT2 neurons: involvement of transcription factors Nrf2 and NF- $\kappa \mathrm{B}, "$ Molecular and Cellular Biochemistry, vol. 337, no. 1-2, pp. 39-51, 2010.

[75] W. Ma, L. Yuan, H. Yu et al., "Genistein as a neuroprotective antioxidant attenuates redox imbalance induced by $\beta$ amyloid peptides 25-35 in PC12 cells," International Journal of Developmental Neuroscience, vol. 28, no. 4, pp. 289-295, 2010.

[76] C. J. Wruck, M. E. Gotz, T. Herdegen, D. Varoga, L. O. Brandenburg, and T. Pufe, "Kavalactones protect neural cells against amyloid $\beta$ peptide-induced neurotoxicity via extracellular signal-regulated kinase $1 / 2$-dependent nuclear factor erythroid 2-related factor 2 activation," Molecular Pharmacology, vol. 73, no. 6, pp. 1785-1795, 2008.

[77] B. Eftekharzadeh, N. Maghsoudi, and F. Khodagholi, "Stabilization of transcription factor Nrf2 by tBHQ prevents oxidative stress-induced amyloid $\beta$ formation in NT2N neurons," Biochimie, vol. 92, no. 3, pp. 245-253, 2010.

[78] H. M. Park, J. A. Kim, and M. K. Kwak, "Protection against amyloid beta cytotoxicity by sulforaphane: role of the proteasome," Archives of Pharmacal Research, vol. 32, no. 1, pp. 109-115, 2009.

[79] V. Dostal, C. M. Roberts, and C. D. Link, "Genetic mechanisms of coffee extract protection in a Caenorhabditis elegans model of $\beta$-amyloid peptide toxicity," Genetics, vol. 186, no. 3, pp. 857-866, 2010.

[80] K. Kanninen, R. Heikkinen, T. Malm et al., "Intrahippocampal injection of a lentiviral vector expressing Nrf2 improves spatial learning in a mouse model of Alzheimer's disease," Proceedings of the National Academy of Sciences of the United States of America, vol. 106, no. 38, pp. 16505-16510, 2009.

[81] M. Salazar, A. I. Rojo, D. Velasco, R. M. De Sagarra, and A. Cuadrado, "Glycogen synthase kinase- $3 \beta$ inhibits the xenobiotic and antioxidant cell response by direct phosphorylation and nuclear exclusion of the transcription factor Nrf2," Journal of Biological Chemistry, vol. 281, no. 21, pp. 1484114851, 2006.

[82] A. I. Rojo, P. Rada, J. Egea, A. O. Rosa, M. G. López, and A. Cuadrado, "Functional interference between glycogen synthase kinase- 3 beta and the transcription factor Nrf2 in protection against kainate-induced hippocampal celldeath," Molecular and Cellular Neuroscience, vol. 39, no. 1, pp. 125132, 2008.

[83] A. K. Jain and A. K. Jaiswal, "Phosphorylation of tyrosine 568 controls nuclear export of Nrf2," Journal of Biological Chemistry, vol. 281, no. 17, pp. 12132-12142, 2006.

[84] A. K. Jain and A. K. Jaiswal, "GSK- $3 \beta$ acts upstream of Fyn kinase in regulation of nuclear export and degradation of NFE2 related factor 2," Journal of Biological Chemistry, vol. 282, no. 22, pp. 16502-16510, 2007.

[85] H. Y. Kay, Y. W. Kim, D. H. Lee, S. H. Sung, S. J. Hwang, and S. G. Kim, "Nrf2-mediated liver protection by sauchinone, an antioxidant lignan, from acetaminophen toxicity through the PKCdelta-GSK3beta pathway," British Journal of Pharmacology. In press.

[86] S. Espada, A. I. Rojo, M. Salinas, and A. Cuadrado, "The muscarinic M1 receptor activates Nrf2 through a signaling cascade that involves protein kinase $\mathrm{C}$ and inhibition of GSK3beta: connecting neurotransmission with neuroprotection," Journal of Neurochemistry, vol. 110, no. 3, pp. 1107-1119, 2009.

[87] J. H. An, K. Vranas, M. Lucke et al., "Regulation of the Caenorhabditis elegans oxidative stress defense protein SKN1 by glycogen synthase kinase-3," Proceedings of the National Academy of Sciences of the United States of America, vol. 102, no. 45, pp. 16275-16280, 2005.

[88] T. Prestera, W. D. Holtzclaw, Y. Zhang, and P. Talalay, "Chemical and molecular regulation of enzymes that detoxify carcinogens," Proceedings of the National Academy of Sciences of the United States of America, vol. 90, no. 7, pp. 2965-2969, 1993.

[89] E. C. Reisinger, P. Kern, M. Ernst et al., "Inhibition of HIV progression by dithiocarb," Lancet, vol. 335, no. 8691, pp. 679-682, 1990.

[90] S. F. Liu, X. Ye, and A. B. Malik, "Inhibition of NF- $\kappa$ B activation by pyrrolidine dithiocarbamate prevents in vivo expression of proinflammatory genes," Circulation, vol. 100, no. 12, pp. 1330-1337, 1999.

[91] R. Schreck, B. Meier, D. N. Mannel, W. Droge, and P. A. Baeuerle, "Dithiocarbamates as potent inhibitors of nuclear factor $\kappa \mathrm{B}$ activation in intact cells," Journal of Experimental Medicine, vol. 175, no. 5, pp. 1181-1194, 1992.

[92] M. Hayakawa, H. Miyashita, I. Sakamoto et al., "Evidence that reactive oxygen species do not mediate NF- $\kappa \mathrm{B}$ activation," EMBO Journal, vol. 22, no. 13, pp. 3356-3366, 2003.

[93] S. Verhaegen, A. J. McGowan, A. R. Brophy, R. S. Fernandes, and T. G. Cotter, "Inhibition of apoptosis by antioxidant in the human HL-60 leukemia cell line," Biochemical Pharmacology, vol. 50, no. 7, pp. 1021-1029, 1995.

[94] A. C. Wild, H. R. Moinova, and R. T. Mulcahy, "Regulation of $\gamma$-glutamylcysteine synthetase subunit gene expression by the transcription factor Nrf2," Journal of Biological Chemistry, vol. 274, no. 47, pp. 33627-33636, 1999.

[95] L. M. Zipper and R. T. Mulcahy, "Erk activation is required for Nrf2 nuclear localization during pyrrolidine dithiocarbamate induction of glutamate cysteine ligase modulatory gene expression in HepG2 cells," Toxicological Sciences, vol. 73, no. 1, pp. 124-134, 2003. 
[96] S. Borrello and B. Demple, "NFא B-independent transcriptional induction of the human manganous superoxide dismutase gene," Archives of Biochemistry and Biophysics, vol. 348, no. 2, pp. 289-294, 1997.

[97] C. L. Hartsfield, J. Alam, and A. M. K. Choi, "Transcriptional regulation of the heme oxygenase 1 gene by pyrrolidine dithiocarbamate," FASEB Journal, vol. 12, no. 15, pp. 16751682, 1998.

[98] K. M. Stuhlmeier, "Activation and regulation of Hsp32 and Hsp70," European Journal of Biochemistry, vol. 267, no. 4, pp. 1161-1167, 2000.

[99] I. Nobel, M. Kimland, B. Lind, S. Orrenius, and A. F. G. Slater, "Dithiocarbamates induce apoptosis in thymocytes by raising the intracellular level of redox-active copper," Journal of Biological Chemistry, vol. 270, no. 44, pp. 26202-26208, 1995.

[100] G.-Y. Liu, N. Frank, H. Bartsch, and J.-K. Lin, "Induction of apoptosis by thiuramdisulfides, the reactive metabolites of dithiocarbamates, through coordinative modulation of $\mathrm{NF} \kappa \mathrm{B}, \mathrm{c}-\mathrm{fos} / \mathrm{c}-\mathrm{jun}$, and 53 proteins," Molecular Carcinogenesis, vol. 22, no. 4, pp. 235-246, 1998.

[101] J. C. Tsai, M. Jain, C. M. Hsieh et al., "Induction of apoptosis by pyrrolidinedithiocarbamate and $\mathrm{N}$-acetylcysteine in vascular smooth muscle cells," Journal of Biological Chemistry, vol. 271, no. 7, pp. 3667-3670, 1996.

[102] R. Chinery, R. D. Beauchamp, Y. Shyr, S. C. Kirkland, R. J. Coffey, and J. D. Morrow, "Antioxidants reduce cyclooxygenase-2 expression, prostaglandin production, and proliferation in colorectal cancer cells," Cancer Research, vol. 58, no. 11, pp. 2323-2327, 1998.

[103] G. Calviello, G. M. Filippi, A. Toesca et al., "Repeated exposure to pyrrolidine-dithiocarbamate induces peripheral nerve alterations in rats," Toxicology Letters, vol. 158, no. 1, pp. 61-71, 2005.

[104] K. C. Chung, J. H. Park, C. H. Kim et al., "Novel biphasic effect of pyrrolidine dithiocarbamate on neuronal cell viability is mediated by the differential regulation of intracellular zinc and copper ion levels, NF- $\kappa \mathrm{B}$, and MAP kinases," Journal of Neuroscience Research, vol. 59, no. 1, pp. 117-125, 2000.

[105] A. Nurmi, G. Goldsteins, J. Närväinen et al., "Antioxidant pyrrolidine dithiocarbamate activates Akt-GSK signaling and is neuroprotective in neonatal hypoxia-ischemia," Free Radical Biology and Medicine, vol. 40, no. 10, pp. 1776-1784, 2006.

[106] T. M. Malm, H. Iivonen, G. Goldsteins et al., "Pyrrolidine dithiocarbamate activates Akt and improves spatial learning in APP/PS1 mice without affecting $\beta$-amyloid burden," Journal of Neuroscience, vol. 27, no. 14, pp. 3712-3721, 2007.

[107] G. W. Verhaegh, M. J. Richard, and P. Hainaut, "Regulation of 553 by metal ions and by antioxidants: dithiocarbamate down-regulates p53 DNA-binding activity by increasing the intracellular level of copper," Molecular and Cellular Biology, vol. 17, no. 10, pp. 5699-5706, 1997.

[108] T. A. Bayer, S. Schäfer, A. Simons et al., "Dietary Cu stabilizes brain superoxide dismutase 1 activity and reduces amyloid A $\beta$ production in APP23 transgenic mice," Proceedings of the National Academy of Sciences of the United States of America, vol. 100, no. 24, pp. 14187-14192, 2003.

[109] C. J. Maynard, R. Cappai, I. Volitakis et al., "Overexpression of Alzheimer's disease amyloid- $\beta$ opposes the age-dependent elevations of brain copper and iron," Journal of Biological Chemistry, vol. 277, no. 47, pp. 44670-44676, 2002.
[110] A. L. Phinney, B. Drisaldi, S. D. Schmidt et al., "In vivo reduction of amyloid- $\beta$ by a mutant copper transporter," Proceedings of the National Academy of Sciences of the United States of America, vol. 100, no. 2, pp. 14193-14198, 2003.

[111] S. H. Chen, J. K. Lin, Y. C. Liang, M. H. Pan, S. H. Liu, and S. Y. Lin-Shiau, "Involvement of activating transcription factors JNK, NF- $\kappa \mathrm{B}$, and AP-1 in apoptosis induced by pyrrolidine dithiocarbamate/Cu complex," European Journal of Pharmacology, vol. 594, no. 1-3, pp. 9-17, 2008.

[112] G. Filiz, K. A. Price, A. Caragounis, T. Du, P. J. Crouch, and A. R. White, "The role of metals in modulating metalloprotease activity in the AD brain," European Biophysics Journal, vol. 37, no. 3, pp. 315-321, 2008. 


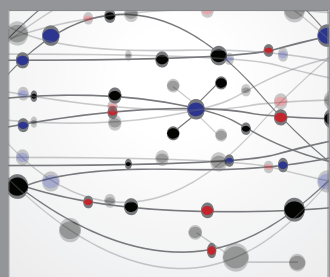

The Scientific World Journal
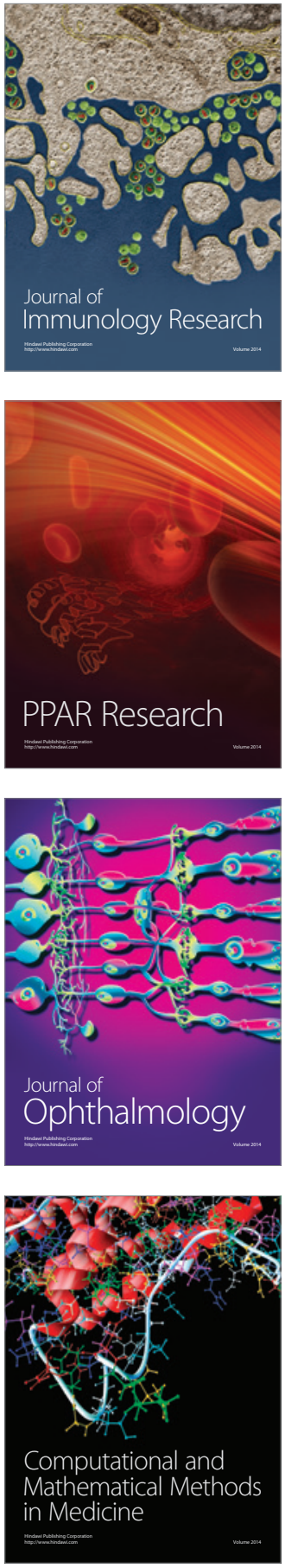

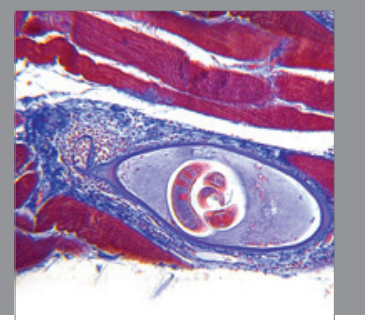

Gastroenterology

Research and Practice
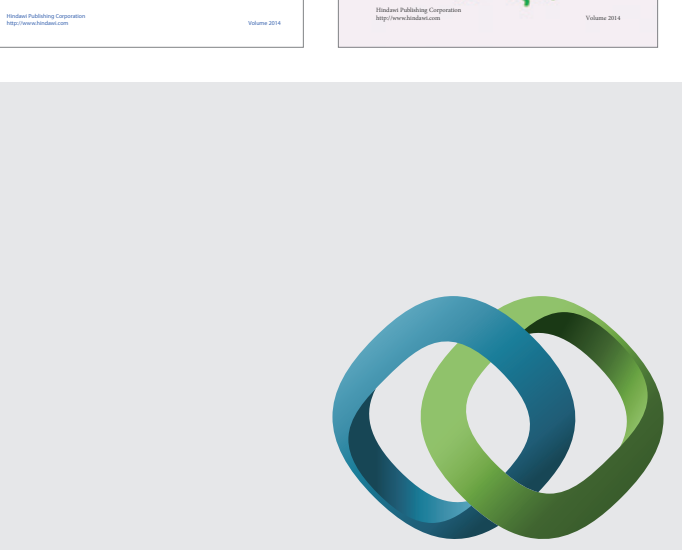

\section{Hindawi}

Submit your manuscripts at

http://www.hindawi.com
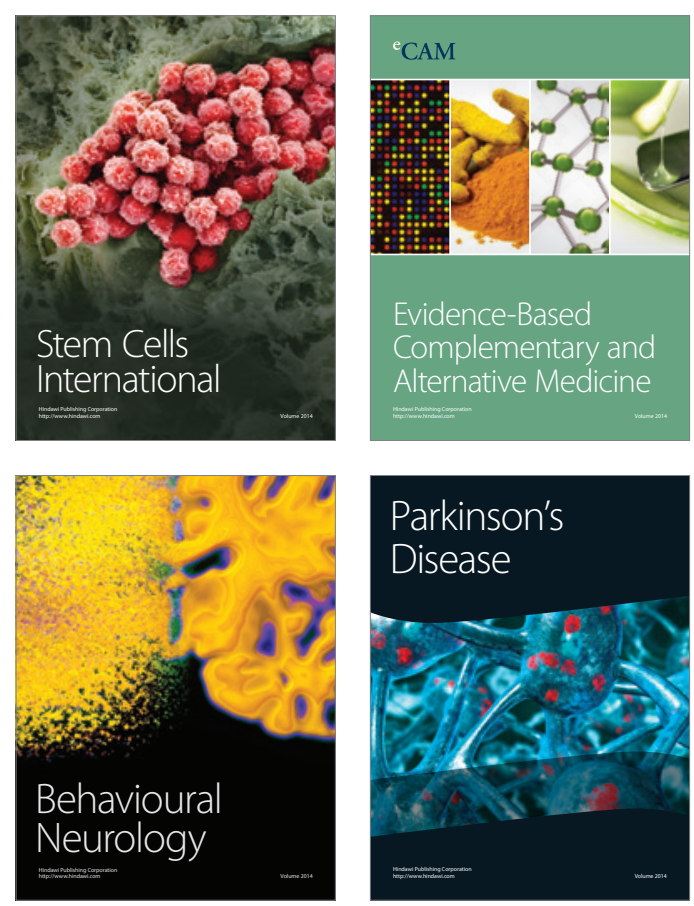

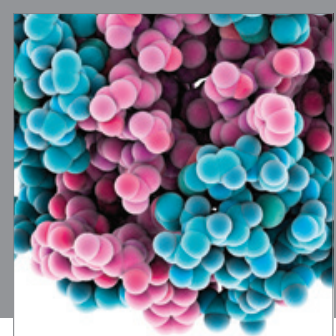

Journal of
Diabetes Research

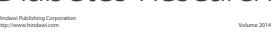

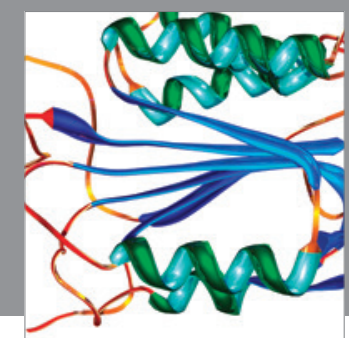

Disease Markers
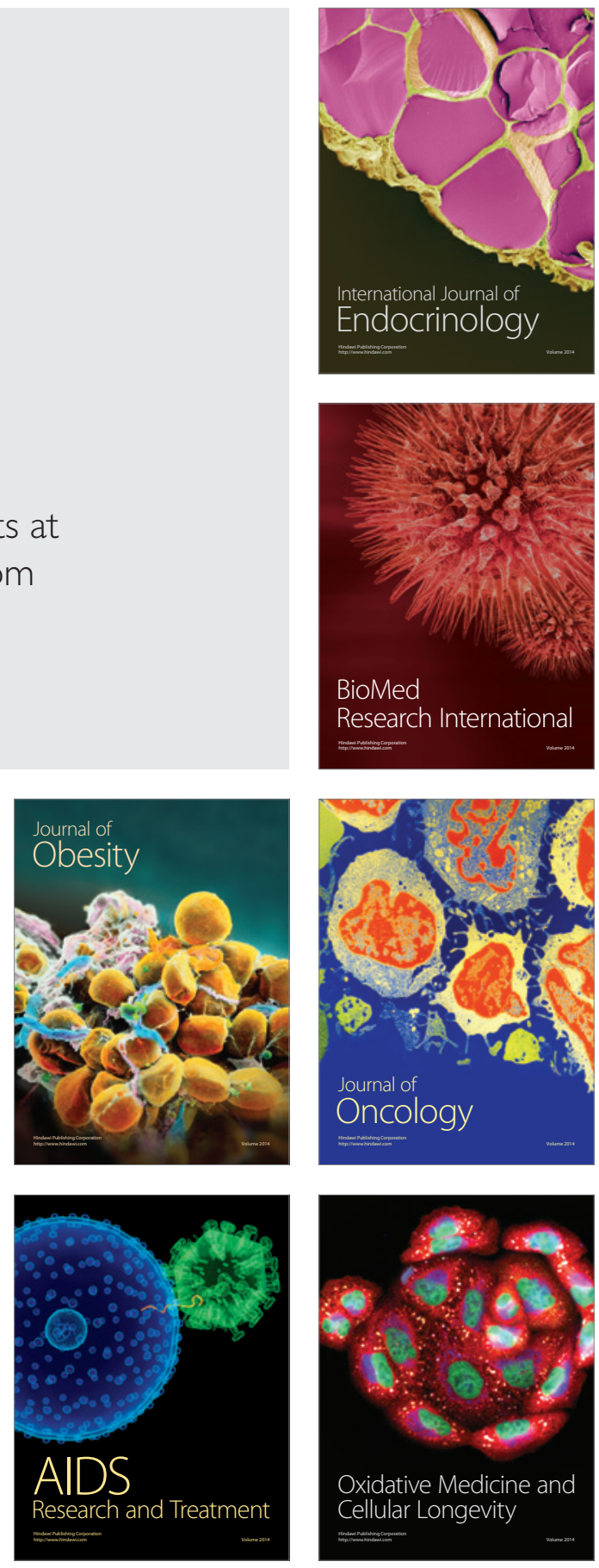